\title{
Impacto do Parfor nas Escolas Públicas do Ensino Fundamental
}

\author{
Valdinei Costa Souza'
}

'Coordenação de Aperfeiçoamento de Pessoal de Nível Superior (CAPES), Brasília/DF - Brasil

RESUMO - Impacto do Parfor nas Escolas Públicas do Ensino Fundamental. Este estudo avalia o impacto do Plano Nacional de Formação de Professores da Educação Básica (Parfor) nas escolas públicas. Operacionalmente, reduziu-se o universo do Parfor aos cursos de Pedagogia e, seus resultados, aos anos iniciais do ensino fundamental. Utilizou-se o método diferenças em diferenças (DD) para avaliar se houve aumento no número de pedagogos em atuação nas escolas públicas beneficiadas, bem como melhoria no Îndice de Desenvolvimento da Educação Básica (Ideb) dessas mesmas escolas. Os resultados apontaram que o Parfor promoveu um pequeno aumento na quantidade de pedagogos nas unidades escolares, mas no que se refere ao Ideb os resultados não foram conclusivos.

Palavras-chave: Parfor. Formação de Professores. Avaliação de Impacto. Diferenças em Diferenças.

\begin{abstract}
Impact of PARFOR on Public Elementary Schools. This study assesses the impact of the Plano Nacional de Formação de Professores da Educação Básica (PARFOR) in public schools. Operationally, the universe of PARFOR was reduced to Pedagogia courses and, its results, to the elementary school. The differences in differences (DD) method was used to assess whether there was an increase in the number of pedagogos, working in the benefited public schools, as well as an improvement in the Índice de Desenvolvimento da Educação Básica (IDEB) of those same schools. The results showed that PARFOR promoted a small increase in the number of pedagogos in school units, but about IDEB, the results were not conclusive. Keywords: PARFOR. Teacher Education. Impact Assessment. Differences in Differences.
\end{abstract}

Educação \& Realidade, Porto Alegre, v. 46, n. 2, e106417, 2021 
Impacto do Parfor nas Escolas Públicas do Ensino Fundamental

\section{Introdução}

Este artigo apresenta os resultados da avaliação do impacto do Plano Nacional de Formação de Professores da Educação Básica (Parfor), aferindo a existência de causalidade entre as ações do Plano, a melhoria do perfil de titulação do quadro docente e a qualidade das escolas públicas de ensino fundamental - anos iniciais. Trata-se de um estudo quantitativo, baseado no método diferenças em diferenças (DD), que busca identificar os efeitos promovidos pelos cursos de Pedagogia do Parfor no número de pedagogos em atuação nas escolas públicas beneficiadas, bem como no Índice de Desenvolvimento da Educação Básica ${ }^{1}$ (Ideb) dessas mesmas escolas.

Este estudo insere-se nas discussões que sinalizam a importância do desenvolvimento de investigações sobre a relação formação de professores e aprendizagem de alunos (Cochran-Smith; Zeichner, 2005; Yoon et al., 2007; Goldhaber, 2013; Sleeter, 2014; AERA, 2015; Rowan et al., 2015; Cochran-Smith et al., 2016). A despeito da relevância que a formação de professores ganhou para as reformas educacionais desenvolvidas por diversos países (OCDE, 2011, 2013, 2018), é relativamente comum encontrar divergências na literatura da área sobre a melhor maneira de desenvolver essa formação, justificando a realização de avaliações que possam contribuir com o levantamento de evidências para suporte ao tema. Além disso, os caminhos metodológicos mais adequados para apurar tais evidências não estão sedimentados, incentivando a realização de experiências para gerar conhecimentos também nesse aspecto.

O Parfor foi criado em 2009 para promover a formação inicial e continuada de profissionais do magistério da rede pública, com vista a superar o déficit de professores diplomados em atuação nas escolas e, ao mesmo tempo, ampliar as condições para a melhora da qualidade do ensino oferecido. Em 2016, a edição do Decreto n. ${ }^{\circ}$ 8.752, de 9 de maio de 2016 (Brasil, 2016) alterou a Política Nacional de Formação de Profissionais do Magistério da Educação Básica ${ }^{2}$ e, por consequência, revogou a base legal $^{3}$ do Parfor. Nesse sentido, como um ponto de inflexão, o novo decreto catalisou a relevância de avaliar os resultados gerados pelo Plano até o momento da mudança.

Do ponto de vista metodológico, o universo desta análise restringiu-se à formação inicial oferecida pelo Parfor, mais precisamente aos cursos de Pedagogia, tendo em vista: i) a importância relativa da formação inicial no conjunto das ações do Parfor; ii) a centralidade da Pedagogia como principal área contemplada pelo Parfor durante o período analisado; iii) a grande demanda das redes públicas de educação por pedagogos diplomados; e, por fim, iv) a necessidade de localizar os impactos gerados pelo Parfor por tipo de formação, separando o argumento interpretativo e viabilizando que as evidências por ele geradas sejam válidas e confiáveis, conforme defendido pela American Educational Research Association (AERA, 2015). 
Cabe destacar ainda que, conceitualmente, avaliação é entendida neste trabalho como juízo de valor legitimado sobre determinado objeto, visando subsidiar a tomada de decisão sobre ele. Com base nesse conceito, assume-se que o juízo de valor advindo do processo avaliativo do Parfor legitima-se quando fundamentado em critérios que refletem o cumprimento (ou não) de seus objetivos, como aqueles definidos no Art. 1. ${ }^{\circ}$ da Portaria Normativa n. ${ }^{\text {9 }}$, de 30 de junho de 2009 (Brasil, 2009b), que estabelece como finalidade do Plano atender à demanda por formação de professores das redes públicas de educação, bem como no Inciso I do Art. 3. ${ }^{\circ}$ do Decreto n. ${ }^{\circ}$ 6.755, de 29 de janeiro de 2009 (Brasil, 2009a), que indica a melhoria da qualidade da educação básica pública como um dos objetivos a serem perseguidos pelas ações do Parfor no período utilizado aqui como referência de análise.

Operacionalmente, tais propósitos foram associados neste trabalho às variáveis proxies: a) número de pedagogos diplomados atuantes nas escolas públicas de ensino fundamental - anos iniciais, referindose ao atendimento à necessidade de formação de professores; e, b) Ideb ${ }^{4}$ calculado para essas mesmas escolas públicas, referindo-se à melhoria da qualidade da educação. Com isso, buscou-se manter uma coerência, no âmbito do recorte sob estudo, entre a variável de causa (titulação em Pedagogia pelo Parfor) e as variáveis de efeito (número de pedagogos diplomados; e, Ideb dos anos iniciais das escolas).

A partir dos caminhos escolhidos, organizou-se este trabalho em quatro partes, excluindo-se esta introdução e as considerações finais. Na primeira, apresentam-se as informações gerais sobre Parfor e os principais números envolvidos na sua execução. Na segunda, analisase o Parfor no contexto da discussão teórica que envolve a formação de professores e a avaliação do seu impacto. Na terceira, descreve-se a metodologia utilizada no estudo e, finalmente, na quarta, apresentam-se os resultados encontrados e algumas recomendações deles advindas. Nas considerações finais, são sinalizados os principais achados, bem como aspectos que poderiam ser contemplados em outras avaliações do Parfor.

\section{Sobre o Parfor}

O Parfor é gerido pela Coordenação de Aperfeiçoamento de Pessoal de Nível Superior (Capes). Até 2016, a execução do Parfor foi dividida em duas: presencial e a distância. O Parfor Presencial concentrou cursos destinados à formação inicial na modalidade presencial de professores das redes públicas estaduais e municipais de educação básica sem formação em nível superior (primeira licenciatura), que atuam em áreas distintas da sua formação inicial (segunda licenciatura) ou que não possuam habilitação em licenciatura (formação pedagógica). Os cursos à distância de formação inicial e continuada de docentes integrantes do Parfor eram fomentados no âmbito da Universidade Aberta do Brasil (UAB). 
Impacto do Parfor nas Escolas Públicas do Ensino Fundamental

A partir de 2016, o novo regramento da Política Nacional de Formação dos Profissionais da Educação Básica (Brasil, 2016) estabeleceu algumas mudanças nas orientações que vinham desde 2009 (Brasil, 2009a). Entre elas, estava a alteração dos objetivos e ações da referida Política, com destaque para a criação de um Programa Nacional de Formação de Profissionais da Educação Básica, possivelmente substituto do Parfor, e de uma prova nacional para docentes. No entanto, cabe destacar que a atual política delineada nos termos do Decreto n. ${ }^{\circ} 8.752$, de 9 de maio de 2016 (Brasil, 2016) ainda não está em vigor por falta de regulamentação, a despeito de já ter revogado a norma anterior.

Considerando os números do Parfor desde a sua instalação em 2009 e até 2014, contabilizam-se mais de 400 mil matrículas de professores da educação básica (Figura 1), notadamente concentradas na modalidade a distância (cerca de $80 \%$ das matrículas). Em relação ao tipo de curso, mais da metade das matrículas do Parfor ocorreram nas licenciaturas, ratificando o seu propósito de contribuir com o cumprimento dos requisitos de formação em nível superior para todos os docentes, conforme previstos na Lei de Diretrizes e Bases da Educação Nacional/ LDB (Brasil, 1996).

Figura 1 - Matriculados no Parfor porTipo de Curso, turmas de 2009 a 2014

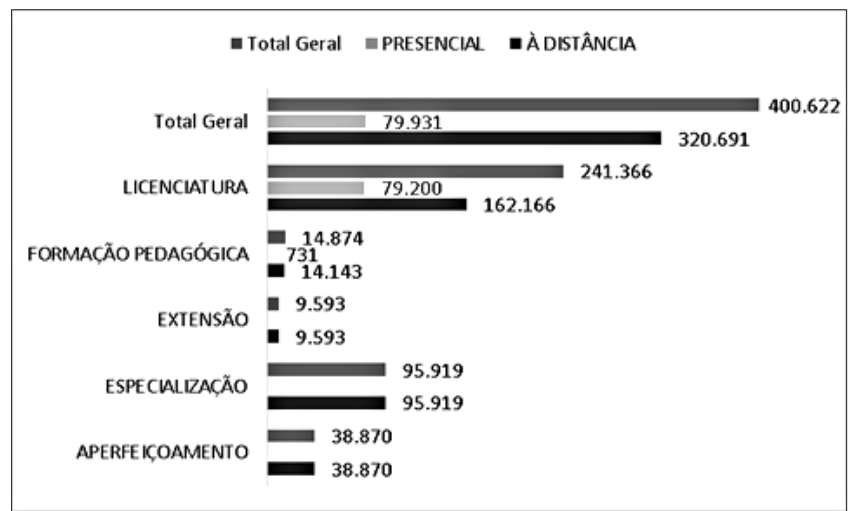

Fonte: Capes/SisUAB/Plataforma Freire (16 jun. 2016).

Conforme dados da Tabela 1, que apresenta a distribuição das matrículas do Plano por área de licenciatura, observa-se que a Pedagogia responde por $28 \%$ dessas matrículas. Em segundo lugar, vem a área de Matemática, com cerca de $13 \%$ do número de matrículas do Plano. Tomando-se apenas as licenciaturas presenciais, a Pedagogia responde sozinha por quase $40 \%$ das matrículas e, na sequência, vem a área de Letras, com $11 \%$ das matrículas dessa modalidade de curso. 
Tabela 1 - Matrículas nas Licenciaturas do Parfor por Áreas de Licenciaturas, Turmas 2009 a 2014

\begin{tabular}{|c|c|c|c|c|c|c|}
\hline \multirow{2}{*}{ ÁREAS } & \multicolumn{2}{|c|}{ A DISTÂNCIA } & \multicolumn{2}{|c|}{ PRESENCIAL } & \multicolumn{2}{|c|}{ TOTAL } \\
\hline & No. & $\%$ & No. & $\%$ & No. & $\%$ \\
\hline Total Geral & 162.166 & $100 \%$ & 79.200 & $100 \%$ & 241.366 & $100 \%$ \\
\hline PEDAGOGIA & 37.079 & $23 \%$ & 30.608 & $39 \%$ & 67.687 & $28 \%$ \\
\hline MATEMÁTICA & 27.554 & $17 \%$ & 4.695 & $6 \%$ & 32.249 & $13 \%$ \\
\hline CIÊNCIAS BIOLÓGICAS & 11.512 & $7 \%$ & 3.021 & $4 \%$ & 14.533 & $6 \%$ \\
\hline LINGUÍSTICA (LÍNGUAS) & 13.833 & $9 \%$ & & $0 \%$ & 13.833 & $6 \%$ \\
\hline HISTÓRIA & 8.987 & $6 \%$ & 3.976 & $5 \%$ & 12.963 & $5 \%$ \\
\hline LETRAS & 1.874 & $1 \%$ & 9.079 & $11 \%$ & 10.953 & $5 \%$ \\
\hline GEOGRAFIA & 7.153 & $4 \%$ & 3.130 & $4 \%$ & 10.283 & $4 \%$ \\
\hline $\begin{array}{l}\text { LINGUÍSTICA DE LÍNGUAS } \\
\text { ESTRANGEIRAS }\end{array}$ & 9.935 & $6 \%$ & & $0 \%$ & 9.935 & $4 \%$ \\
\hline FÍSICA & 8.286 & $5 \%$ & 920 & $1 \%$ & 9.206 & $4 \%$ \\
\hline QUÍMICA & 6.230 & $4 \%$ & 724 & $1 \%$ & 6.954 & $3 \%$ \\
\hline EDUCAÇÃO FÍSICA & 2.989 & $2 \%$ & 3.916 & $5 \%$ & 6.905 & $3 \%$ \\
\hline FILOSOFIA & 4.532 & $3 \%$ & 507 & $1 \%$ & 5.039 & $2 \%$ \\
\hline BIOLOGIA & 4.728 & $3 \%$ & & $0 \%$ & 4.728 & $2 \%$ \\
\hline CIÊNCIAS & 837 & $1 \%$ & 2.265 & $3 \%$ & 3.102 & $1 \%$ \\
\hline EDUCAÇÃO A DISTÂNCIA & 3.057 & $2 \%$ & & $0 \%$ & 3.057 & $1 \%$ \\
\hline $\begin{array}{l}\text { FOR. DE PROFESSOR PARA A } \\
\text { EDUCAÇÃO BÁSICA }\end{array}$ & 2.723 & $2 \%$ & & $0 \%$ & 2.723 & $1 \%$ \\
\hline INFORMÁTICA & & $0 \%$ & 2.563 & $3 \%$ & 2.563 & $1 \%$ \\
\hline ARTES & & $0 \%$ & 2.402 & $3 \%$ & 2.402 & $1 \%$ \\
\hline ARTES VISUAIS & 1.459 & $1 \%$ & & $0 \%$ & 1.459 & $1 \%$ \\
\hline $\begin{array}{l}\text { LÍNGUAS/LIT. ESTRANGEIRAS } \\
\text { MODERNAS }\end{array}$ & 1.453 & $1 \%$ & & $0 \%$ & 1.453 & $1 \%$ \\
\hline OUTRAS & 7.945 & $5 \%$ & 11.394 & $14 \%$ & 19.339 & $8 \%$ \\
\hline
\end{tabular}

Aparentemente, essa concentração da oferta de cursos do Parfor na formação inicial de professores e, mais especificamente, na área de Pedagogia se justifica pelos dados apresentados pela Sinopse Estatística do Professor da Educação Básica (Inep, 2009). De acordo com essa Sinopse, quando o Parfor foi criado em 2009, cerca de 637.000 professores das escolas do país não possuíam formação superior ( $30 \%$ do total do universo de quase dois milhões de docentes). Especificamente na Educação Infantil e nos anos iniciais do Ensino Fundamental, os indicadores de formação eram ainda piores que a média geral: respectivamente $52 \%$ e $38 \%$ dos professores nesses níveis de atuação escolar não possuíam a formação profissional exigida legalmente. Dessa forma, podese apreender que o Parfor atuou justamente nos níveis escolares com maior deficiência de professor com formação adequada. 
Do ponto de vista da conclusão dos alunos por tipo de cursos, a Figura 2 confirma a maior quantidade de alunos no Parfor nos cursos à distância. No entanto, essa superioridade numérica de concluintes explica-se pelos egressos dos cursos de especialização, aperfeiçoamento e extensão à distância. No que se refere às licenciaturas, a oferta presencial é responsável pela maior parte dos egressos no período em análise, ainda que tenha recebido menos da metade das matrículas da oferta a distância.

Figura 2 - Concluintes do Parfor por Tipo de Curso, turmas de 2009 a 2014

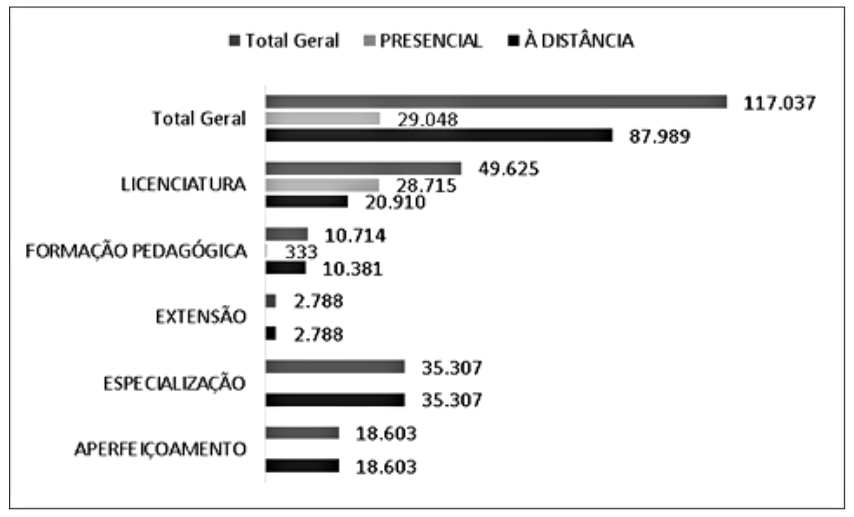

Fonte: Capes/SisUAB/Plataforma Freire (16 jun. 2016).

Considerando que o Parfor se destina à formação de professores de escolas públicas, foi realizado o cruzamento entre a base do Parfor com o Censo Escolar 2015. Os achados estão sistematizados pela Figura 3. Eles apontam que cerca de um terço dos alunos formados ou cursando a licenciatura presencial e dois terços dos alunos formados ou cursando a licenciatura a distância não foram listados como professores da educação básica. Mesmo considerando a possibilidade de os professores pedirem demissão das redes estaduais e municipais de educação durante ou após a conclusão do curso, os percentuais de participantes do Parfor fora do Censo Escolar 2015 parecem muito maiores do que o esperado para tais casos. Esse fato indica a necessidade de um maior controle do Plano quanto à seleção do perfil de alunos, definida como professores da rede pública. 
Figura 3 - Registro no Censo Escolar/2015 dos Alunos Formados ou Cursando Licenciatura em Pedagogia pelo Parfor

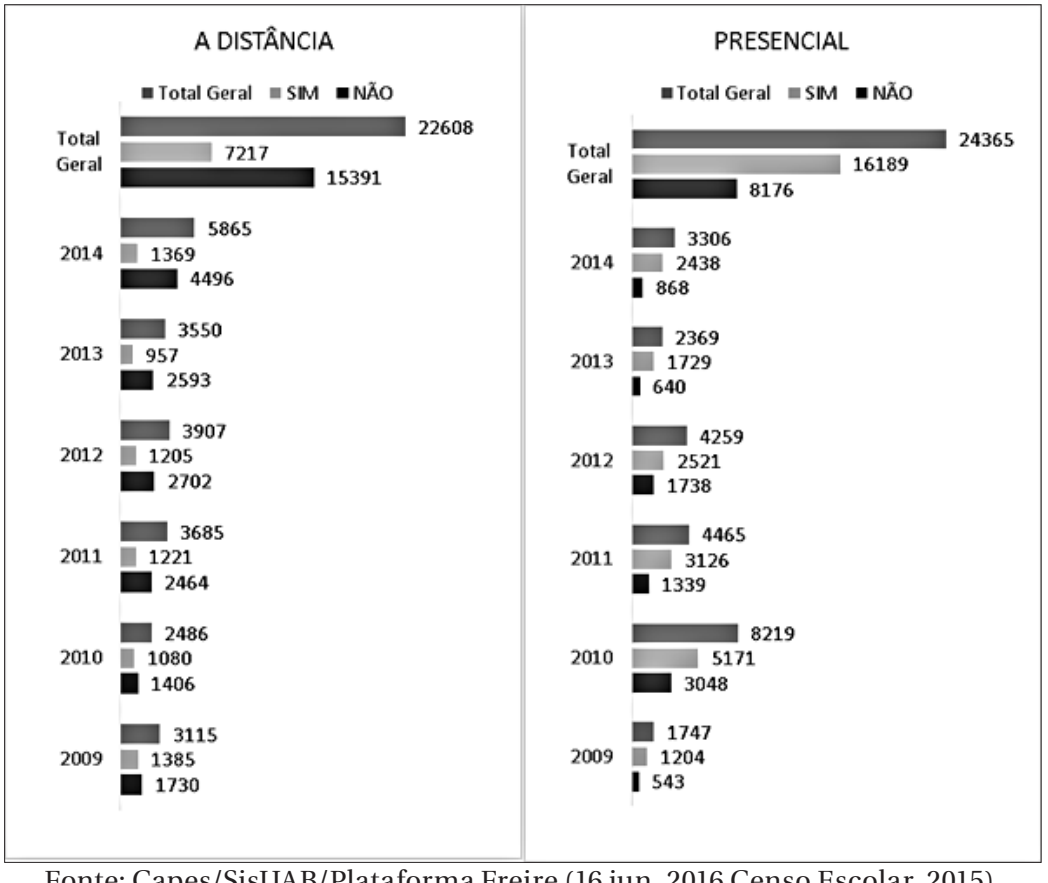

Assim, em linhas gerais, os dados aqui apresentados permitem traçar um panorama das ações do Parfor entre os 2009 e 2014. Tomando-se por referência esses dados, notadamente aqueles relativos aos cursos de Pedagogia, buscou-se identificar os impactos gerados pelas ações do Parfor, respectivamente, no número de pedagogos em atuação nas escolas e na qualidade apresentada por elas. A referência teóricometodológica utilizada nessa análise, bem como os resultados encontrados estão especificados nas seções que seguem.

\section{A Formação de Professores e a Avaliação do seu Impacto}

Considerando as contribuições de Cochran-Smith e Zeichner (2005) e os objetivos deste estudo, a presente análise foi estruturada a partir de dois aspectos teóricos articulados entre si. Primeiro, no reconhecimento de que as diferentes abordagens sobre formação de professores repercutem não só nas discussões acadêmicas sobre o tema, mas também na formulação de políticas públicas. Segundo, na verificação da carência de estudos sobre o impacto da formação docentes destacando-se a necessidade de discutir, também, os desenhos de pesquisa mais apropriados à identificação das referidas evidências.

Do ponto de vista das discussões acadêmicas sobre formação de professores e sua repercussão, Darling-Hammond e Youngs (2002) 
Impacto do Parfor nas Escolas Públicas do Ensino Fundamental

ilustram divergências de concepções e análises empíricas que ocorreram nos EUA em torno da relação entre formação, certificação dos professores e sua eficácia em sala de aula (características dos professores versus características dos programas formativos); sobre a definição dos componentes mais importantes para a eficácia docente (competências), assim como sobre os benefícios (ou não) de programas alternativos de formação docente, quando comparados aos programas formativos tradicionais de preparação dos professores para o trabalho.

No Brasil, ao longo dos últimos anos, tem sido possível observar divergências entre concepções sobre o que é mais adequado para formar professores. Segundo Araújo (2009), tais concepções orbitam em torno de três abordagens teóricas, a saber: racionalidade técnica (enfatiza o conhecimento teórico para instrumentalizar a solução de problemas), racionalidade prática (enfatiza o conhecimento decorrente da prática, por meio da reflexão sobre a ação e voltada à realidade concreta) e racionalidade crítica (enfatiza o conhecimento voltado a reflexões para a compreensão e a transformação social).

Todavia, há autores como Rios (2010), que argumentam em prol de uma perspectiva plural na formação de professores, na qual as dimensões técnica, estética ou criativa, ética e de solidariedade política apresentam-se como um todo articulado entre si. Libâneo (2008) também compartilha de uma visão integradora das abordagens de formação docente, pontuando que o melhor programa para formar o professor é aquele que articula, no seu conjunto, cultura científica, conteúdos instrumentais, espaços de aprendizagem, além de convicções éticas e políticas, sem espaço para qualquer reducionismo em sua abordagem.

Tais diferenças de concepções reverberaram em mudanças recorrentes nas diretrizes nacionais que orientam a formação inicial de professores (Brasil, 2002, 2015, 2019). Especificamente no que se refere às diretrizes que orientam a formação de pedagogos, também foi possível observar embates em torno da base docente ${ }^{5}$ (Franco; Libâneo; Pimenta, 2007; Scheibe, 2007), repercutindo em opiniões diversas sobre a melhor maneira de formar esses professores para atuação na Educação Infantil e nos anos iniciais do Ensino Fundamental, bem como na própria organização dos cursos.

Pesquisadores como Gatti (2010) e Mascarenhas e Franco (2017) evidenciam que as licenciaturas brasileiras, em geral, e a Pedagogia, em particular, apresentam problemas relacionados aos conteúdos abordados nos cursos formativos, os quais podem comprometer a atuação dos professores em sala de aula e, por consequência, a própria aprendizagem dos alunos. No que concerne à oferta específica dos cursos de Pedagogia pelo Parfor, o estudo apresentado por Souza (2017) sinaliza para a ausência de um modelo formativo que possa caracterizar o Parfor presencial como uma unidade. Segundo a autora, diferentes concepções de formação docente coexistem na execução do Plano, sem que ocorram articulações em torno de fundamentos basilares, compartilhados pelos cursos como uma unidade formativa. Foi identificado que os cursos oferecidos pelo Parfor fizeram uso tanto de projetos pedagógicos novos, 
especialmente desenhados para atender à formação de professores leigos, quanto de projetos regulares, destinados à formação de professores que nunca exerceram a profissão. Além disso, foi observada uma diversidade na definição do perfil do egresso formado, da prática de estágio e das atividades complementares, entre outros aspectos, que não permitem associar a oferta do Parfor a uma proposta específica e unitária de formação de professores.

Essa visão fragmentada do Parfor como projeto formativo pode ser considerada sui generis dentro do espectro de estudos revisados para esta pesquisa, na grande maioria realizados no exterior. Em geral, os programas formativos analisados contam com uma caracterização própria, visando diferenciar as experiências entre si e localizar aquilo que é mais eficiente em termos da aprendizagem dos alunos. No caso dessa análise do impacto do Parfor, pelas próprias características do Plano, não foi possível sinalizar, entre a diversidade de propostas formativas, quais delas possuem abordagens mais eficientes em relação às variáveis de efeito observadas.

Quanto aos desenhos metodológicos de pesquisas com foco no impacto da formação de docentes, encontrou-se em Yoon et al. (2007) a ideia de que a randomização de amostras se configura como um dos elementos fundamentais para a validade dos resultados encontrados. Segundo afirmam, a observação sistemática realizada a partir de casos aleatoriamente escolhidos é um instrumento poderoso para descartar explicações concorrentes em torno das mesmas características de programas formativos. Os autores também defendem que os desenhos de pesquisa devem quantificar, separadamente, o valor agregado pela formação dos professores nos currículos, nas metodologias de ensino, na elaboração de materiais didáticos inovadores, bem como na aprendizagem dos alunos. Além disso, conforme recomendam, um projeto de pesquisa rigoroso deve possuir descobertas válidas externamente; poder estatístico adequado para detectar efeitos verdadeiros e tempo suficiente entre o desenvolvimento profissional; e a medição dos resultados dele decorrentes.

Boyd et al. (2006) também detalharam os desafios metodológicos que precisam ser superados para que pesquisas como essas possam ser validadas. Entre esses aspectos, três, em especial, ajudam a iluminar o presente estudo, a saber: a questão do viés de seleção, a dificuldades em documentar recursos programáticos dos cursos formativos e os desafios de estimar os efeitos dos professores no desempenho dos alunos.

$\mathrm{O}$ viés de seleção está relacionado à capacidade de os casos sob estudo representarem, efetivamente, a população investigada. Ele ocorre quando a escolha da amostra privilegia características que interferem na relação entre as variáveis estudadas e terminam por condicionar, por si, os resultados encontrados. Exemplo disso pode ser observado no caso de existir desequilíbrio, entre grupos que estão sendo comparados, de variáveis que podem contaminar o resultado apurado, como nota de desempenho em disciplinas do curso formativo, entre outras. Para evitar situações como essa, torna-se importante que as amostras 
Impacto do Parfor nas Escolas Públicas do Ensino Fundamental

selecionadas para os estudos sejam escolhidas probabilisticamente, de forma que os casos a serem comparados possuam características heterogêneas, sem o privilégio de aspectos específicos que possam influenciar o resultado final encontrado.

No que tange ao desafio de evitar o viés de seleção, é importante citar o estudo de Mihaly et al. (2012), que procurou controlar o viés contextual da escola, ao inseri-la como efeitos fixos nos modelos de desempenho utilizados para estimar os controles dos efeitos do programa de preparação para o ambiente escolar. Tal controle se estabelece estudando-se as diferenças entre os resultados dos alunos de uma mesma escola, e não de qualquer escola. Esse cuidado permite uma maior aproximação dos resultados encontrados, retirando o componente contextual do ambiente escolar como um dos fatores intervenientes dos resultados apurados. Nesta análise do Parfor, buscou-se localizar a unidade de análise na escola para atender justamente a essa recomendação, evitando as interveniências do contexto escolar nos resultados apurados.

Já no que se refere às dificuldades em documentar recursos programáticos dos cursos, o problema relaciona-se, principalmente, à questão da existência de bancos de dados confiáveis sobre a estrutura dos cursos de formação de professores, bem como da definição de elementos-chave que possam diferenciar adequadamente um curso formativo de outros. No caso particular do Parfor, inexiste banco de dados que catalogue e diferencie as abordagens dos cursos de licenciatura oferecidos. Tal ausência constitui, portanto, uma importante barreira para aferir a relação de causalidade entre características específicas de programas formativos e sua repercussão na aprendizagem de alunos. Assim, por ausência de dados, as diferenças entre experiências formativas dos cursos de Pedagogia do Parfor não foram consideradas.

No que tange aos desafios de estimar os efeitos dos professores no desempenho dos alunos, é necessário superar o viés de aferição. Esse tipo de viés ocorre quando a medida utilizada não garante a comparabilidade de respostas entre os grupos. Em geral, está associado à utilização de testes não padronizados para medir a aprendizagem dos alunos. Se os testes de desempenho não forem comparáveis, os resultados deles advindos também não o serão e, portanto, comprometeriam as análises realizadas com base neles. No caso específico deste estudo, ao se optar pela aferição do impacto do Parfor no Ideb calculado para as escolas, levou-se em consideração a comparabilidade entre os indicadores gerados tanto interescolas quanto intraescolas ao longo do tempo. Grosso modo, o valor do Ideb considera as médias de desempenho dos alunos da $4^{\mathrm{a}}$ série $/ 5^{\mathrm{o}}$ ano do ensino fundamental na Prova Brasil, em relação ao tempo médio que os alunos levam para concluir a referida série/ano, por unidade de referência (Fernandes, 2007). Como a Prova Brasil leva em conta o desempenho dos alunos aferido por meio de técnicas como a Teoria de Resposta ao Item (TRI), isso permite que o grau de dificuldade entre os testes aplicados ao longo do tempo e entre grupos distintos se mantenham comparáveis e, portanto, contribui com a validade das análises apresentadas neste artigo. 
Por fim, cabe destacar que, em 2015, a AERA, representando os pesquisadores educacionais a ela associados, publicou uma declaração que analisou o contexto do uso de modelos estatísticos para apurar a relação entre a qualidade da formação do professor e o desempenho escolar dos alunos (AERA, 2015). Essa declaração considerou os principais problemas psicométricos envolvidos, bem como a validade de inferências realizadas com base neles, tendo em vista o desafio de isolar as contribuições de professores e líderes de escolas de muitos outros fatores que moldam a aprendizagem do aluno. Em síntese, essa declaração especificou oito requisitos técnicos que devem ser atendidos para que tais mensurações sejam precisas, confiáveis e válidas, a saber:

(1) As medidas de desempenho dos alunos utilizadas para explicar a influência (ou não) do programa formativo nesse resultado devem estar ancoradas em avaliações que atendem aos padrões profissionais de confiabilidade e validade.

(2) As mensurações realizadas devem tratar de forma separada cada argumento interpretativo (professores, líderes, programas, escolas), constituindo-se como evidência válida e confiável para cada afirmação e interpretação realizadas com base nelas.

(3) As mensurações devem se basear em vários anos de dados de número suficiente de alunos.

(4) As mensurações devem ser calculadas apenas a partir das pontuações nos testes, os quais precisam ser comparáveis ao longo do tempo.

(5) As mensurações não devem ser calculadas com base nas notas nem nas matérias onde não há avaliações padronizadas acompanhadas de evidências de sua confiabilidade e validade.

(6) As mensurações nunca devem ser usadas sozinhas ou isoladamente em sistemas de avaliação de educadores ou programas.

(7) Os sistemas de avaliação que usam mensurações com base estatística das relações de causalidades entre programas formativos e desempenho escolar de alunos devem incluir monitoramento contínuo da qualidade técnica e validade do uso.

(8) Os relatórios e determinações de avaliação baseada em mensurações estatísticas de causalidade devem incluir estimativas de erro associadas ao desempenho dos alunos.

No caso desta avaliação de impacto do Parfor e dos indicadores proxies aqui considerados, buscou-se atender a tais recomendações uma vez que a análise desenvolvida se ancora em medidas confiáveis e válidas para apurar o desempenho dos alunos e sua mensuração para a unidade escolar, bem como na possibilidade de comparar a evolução do número de pedagogo informado no Censo Escolar e do Ideb, calculado para a escola ao longo do tempo. Além disso, buscou avaliar o programa sem isolar os resultados apurados apenas em uma única variável, evitando-se utilizar a aprendizagem do aluno de forma isolada, descontextualizada da unidade escolar. Por último, para garantir a mensuração 
Impacto do Parfor nas Escolas Públicas do Ensino Fundamental

de estatísticas válidas, que incluísse a probabilidade de erro associado, escolheu-se o método diferenças em diferenças (DD), no intuito de minimizar as intercorrências de variáveis não controladas no impacto verificado, conforme explicitado detalhadamente na seção que segue.

\section{Desenho Metodológico}

Uma análise de impacto envolve a necessidade de estabelecer desenhos experimentais ou, neste caso do Parfor, quase-experimentais, que buscam controlar estatisticamente as diferenças entre os resultados apurados no grupo que sofreu a ação (grupo de tratamento) e os resultados apresentados pelo grupo que não sofreu a ação (grupo de controle). Conforme esclarecem Schneider et al. (2007), nesses desenhos são utilizadas técnicas estatísticas para fazer inferências causais sobre o efeito provocado por uma determinada ação, buscando afastar a interferência de outros fatores que podem concorrer com o efeito apurado. Com isso, os resultados alcançados são sempre uma probabilidade de que o efeito foi alcançado, não o efeito em si. Na busca por explicitar o impacto da formação de pedagogos promovida pelo Parfor no desempenho das escolas públicas de ensino fundamental - anos iniciais, optou-se pela utilização do método estatístico DD. Essa técnica permite que algumas das preocupações com a mensuração de impacto de programas formativos possam ser superados: são as mesmas escolas, tanto no controle quanto no tratamento, que são observadas em tempos distintos. Além disso, permite contornar vieses advindos de condições contextuais diferentes, por meio da escolha aleatória das escolas participantes, conforme recomendado por Yoon et al. (2007).

A redução de vieses contextuais é possível porque o DD se baseia nas diferenças observadas entre o incremento das mudanças ocorridas no grupo de tratamento (escolas que receberam a ação do Parfor/ licenciatura em Pedagogia) em relação ao ocorrido no grupo de controle (escolas que não receberam qualquer ação do Parfor). Para tanto, observa-se as trajetórias de ambos os grupos, projetando como trajetória do grupo de controle o que seria a trajetória do grupo de tratamento na ausência do programa, de forma a tratar adequadamente os vieses promovidos por outros fatores que podem intervir no efeito ao longo do tempo.

O primeiro registro no uso do DD está no estudo de Card e Krueger (1994). Essa metodologia tem sido utilizada de forma crescente em estudos que buscam mensurar os impactos de políticas públicas, notadamente aqueles realizados no exterior (Hanushek; Wöbmann, 2006; Heckman; Ichimura; Todd, 1997; Dimick; Ryan, 2014; Solé-Ollé; Sorribas-Navarro, 2008), mas também no Brasil (Firpo; Pieri, 2012; Silva Júnior; Pedrosa; Silva, 2013). O DD é particularmente indicado para casos nos quais não há seleção aleatória dos componentes do grupo de tratamento, há heterogeneidade entre seus componentes em relação a características não observáveis e há informações sobre os componentes dos grupos de controle e tratamento tanto no período anterior quanto no período posterior ao programa. 
Matematicamente, o DD executa a análise de uma dupla diferença: primeira, entre os resultados apresentados antes e depois da ação, tanto para o grupo controle, quanto para o grupo tratamento; e, segunda, a diferença entre as duas diferenças apuradas para verificar o impacto líquido da ação no grupo de tratamento, conforme expressão y = $\alpha+\beta_{d} D+\beta_{t} T+\beta_{d t} D T$, ilustrada na Figura 4 .

\section{Figura 4 - Modelo Matemático Diferenças em Diferenças (DD)}

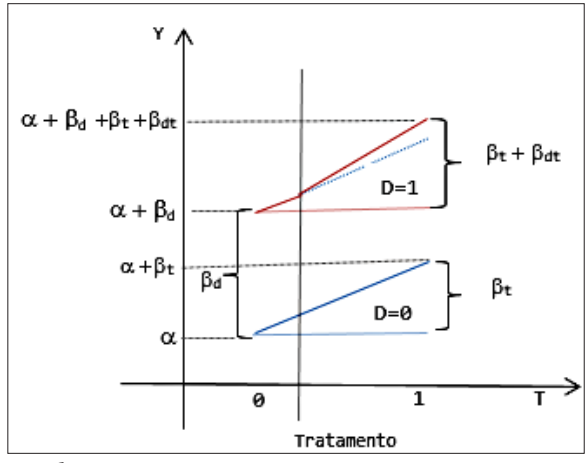

Onde:

D define o tipo de grupo, podendo assumir valor igual a 1 (grupo de tratamento) ou valor igual a 0 (grupo de controle).

$\mathrm{T}$ define o tempo a que ser refere a medida, assumindo-se $\mathrm{T}=0$ para o momento antes da ação; $\mathrm{T}=1$ para o momento após a ação. $\alpha$ representa o "intercepto" do modelo, ou seja, a média global da resposta no grupo de controle antes da aplicação da política. $\beta$ é o coeficiente gerado pelo modelo de regressão para cada um dos pontos principais da função, aferido por meio do cálculo da diferença em diferença, a saber:

(a) Para a diferença entre o início e fim do período no grupo de controle: $\left(\alpha+\beta_{t}\right)-(\alpha)=\beta_{t}$

(b) Para a diferença entre o início e fim do período no grupo de tratamento: $\left(\alpha+\beta_{d}+\beta_{t}+\beta_{d t}\right)-\left(\alpha+\beta_{d}\right)=\beta_{t}+\beta_{d}$

(c) Para a diferença em diferença: $\left(\beta_{t}+\beta_{d t}\right)-\left(\beta_{t}\right)=\beta_{d t}$

\section{Fonte: A Pesquisa.}

A Figura 4 descreve que a primeira diferença (a) refere-se ao grupo de controle. Ela é obtida comparando-se a mudança apurada no fim do período com aquela existente no início do período avaliado. De forma semelhante, é apurada a mudança ocorrida no grupo de tratamento (b). A diferença em diferença (c) refere-se, então, ao impacto obtido pela ação que se quer medir. Essa última diferença refere-se ao impacto que se procura, uma vez que o efeito apurado no grupo de tratamento é descontado daquele efeito identificado no grupo controle.

Para aplicação o método DD no universo de análise do Parfor, foi criada uma base com informações coletadas a partir de diversas fontes, conforme especificado no Quadro 1. 
Impacto do Parfor nas Escolas Públicas do Ensino Fundamental

\begin{tabular}{|c|c|}
\hline \multicolumn{2}{|c|}{ Quadro 1 - Base de Dados da Pesquisa } \\
\hline Informações sobre ... & Fontes \\
\hline $\begin{array}{l}\text { Professores em formação atendidos pelo Parfor e a } \\
\text { identificação de suas escolas de atuação }\end{array}$ & $\begin{array}{l}\text { SisUAB } \\
\text { Plataforma Freire }^{2} \\
\text { Censo Escolar } 2009 \text { e } 2015\end{array}$ \\
\hline $\begin{array}{l}\text { Características das Escolas (quantidade de professores } \\
\text { por área etc.) }\end{array}$ & Censo Escolar 2009 e 2015 \\
\hline $\begin{array}{l}\text { Desempenho dessas escolas nos indicadores de quali- } \\
\text { dade da educação básica. }\end{array}$ & Ideb 2009 e 2015 \\
\hline
\end{tabular}

Na montagem da base de dados da pesquisa, foram adotados alguns tratamentos para garantir a consistência dos dados, tais como: a) excluir da Plataforma Freire dados sobre os professores em formação, cuja situação de matrícula era vazio (professores inscritos, mas não efetivamente matriculados); b) descartar todos os dados relativos aos cursos a distância registrados na Plataforma Freire, priorizando-se os registros vindos do SisUAB para cursos oferecidos nessa modalidade; e c) separar os registros no SisUAB entre aqueles específicos do Parfor dos demais cursos, excluindo-se da análise os registros de alunos de bacharelado, cursos sequenciais e cursos tecnológicos. Para identificar os cursos de formação continuada a distância pertencentes ao Parfor, utilizou-se como regra considerar apenas áreas ${ }^{6}$ de conhecimento diretamente ligadas às licenciaturas, em específico, e à educação, em geral, registradas nos sistemas.

Uma vez identificados os registros dos professores/alunos em formação beneficiados pelo Parfor, eles foram cruzados com os dados do Censo Escolar 2015 e, posteriormente, com a base do Ideb (anos iniciais). Como resultado dos cruzamentos, foram montadas duas tabelas. A primeira, contendo 400.622 registros de alunos do Parfor matriculados entre 2009 e 2014, fornecendo informações sobre os alunos, cursos realizados ou em realização, bem como sobre as escolas que esses alunos do Parfor estavam atuando como professor em 2015. A segunda, contendo 26.918 registros de escolas listadas no Censo Escolar 2015, para as quais foram identificados os cálculos do Ideb das escolas de anos iniciais do ensino fundamental, referentes aos anos-base 2009 (antes do Parfor) e 2015 (depois do Parfor), bem como o número de professores formados na área de Pedagogia, conforme dados do Censo Escolar 2009 e 2015. Nesse segundo arquivo, foram agregadas outras totalizações referentes ao Parfor, como o número de concluintes de Pedagogia do Parfor em cada escola participante, assim como o número de matriculados na formação inicial e na formação continuada que atuavam como professores. Com base nesse segundo arquivo, as escolas foram selecionadas para compor o grupo de tratamento (caso possuíssem pelo menos um professor formado em Pedagogia pelo Parfor até 2014) e o grupo de controle (caso não possuíssem registro de professores matriculados em turmas do Parfor, seja de formação inicial, seja de formação continuada). 
O grupo de tratamento foi formado por todas as 1388 escolas ativas no Censo Escolar de 2015 que contabilizavam professores formados em Pedagogia pelo Parfor. Essas escolas apresentavam entre 1 e 10 professores nessa situação. A maior frequência encontrada foi a de um professor titulado em Pedagogia do Parfor por escola (das 1388 escolas integrantes do grupo de tratamento, 1120 possuíam apenas 1 docentes que concluiu o curso em foco).

Uma vez definido o grupo de tratamento, foram selecionadas aleatoriamente outras 1388 escolas para compor o grupo de controle, desde que não tivesse professores beneficiados pelo Parfor em qualquer das suas modalidades. A distribuição das escolas selecionadas na amostra de pesquisa por região geográfica está disponibilizada na Tabela 2.

Tabela 2 - Distribuição da Amostra de Pesquisa por Região

\begin{tabular}{l|r|r|r}
\hline REGIÃO & CONTROLE & TRATAMENTO & TOTAL GERAL \\
\hline Centro-Oeste & 129 & 32 & 161 \\
\hline Nordeste & 400 & 524 & 924 \\
\hline Norte & 92 & 130 & 222 \\
\hline Sudeste & 569 & 355 & 924 \\
\hline Sul & 198 & 347 & 545 \\
\hline Total Geral & 1388 & 1388 & 2776 \\
\hline
\end{tabular}

Fonte: Dados da Pesquisa.

Uma vez selecionados os dados necessários para a análise, o impacto do Parfor nas escolas públicas foi calculado por meio do SAS Enterprise Guide (SAS) - pacote estatístico da Statistical Analysis System. Para tanto, foi utilizada a proc genmod e os dados no formato long (tempo - antes/depois em linhas, duplicando-se os registros em análise). A estimativa do DD para o impacto em análise está disposta na seção que se segue.

\section{Impacto do Parfor na Educação Básica}

A avaliação do impacto da formação oferecida pelo Parfor aos professores das redes públicas de educação básica, por meio dos cursos de Pedagogia nas modalidades presencial e a distância, revelou que o Plano conseguiu aumentar, mesmo que de forma relativamente pequena, a quantidade de pedagogos atuantes nas escolas beneficiadas. No entanto, no que tange ao seu impacto no desempenho dessas mesmas escolas no Ideb, não foi possível encontrar qualquer relação estatisticamente válida.

De acordo com os dados, as ações do Parfor contribuíram positivamente para alterar o quadro da carência de professores com a titulação mínima exigida em lei para atuação na educação infantil e nos anos iniciais do ensino fundamental. Como pode ser observado na Tabela 3 , as estimativas do DD indicaram que as escolas que participaram do Parfor têm em torno de um pedagogo a mais do que teriam se não par- 
Impacto do Parfor nas Escolas Públicas do Ensino Fundamental

ticipassem do Plano (estimate $=1.0893$ ), com probabilidade, aproximadamente, de apenas $0,1 \%(\operatorname{Pr}>|z|)$ de que essa estimativa esteja errada.

Tabela 3 - Efeito do Parfor no Número de Pedagogos - 2009 vs. 2015

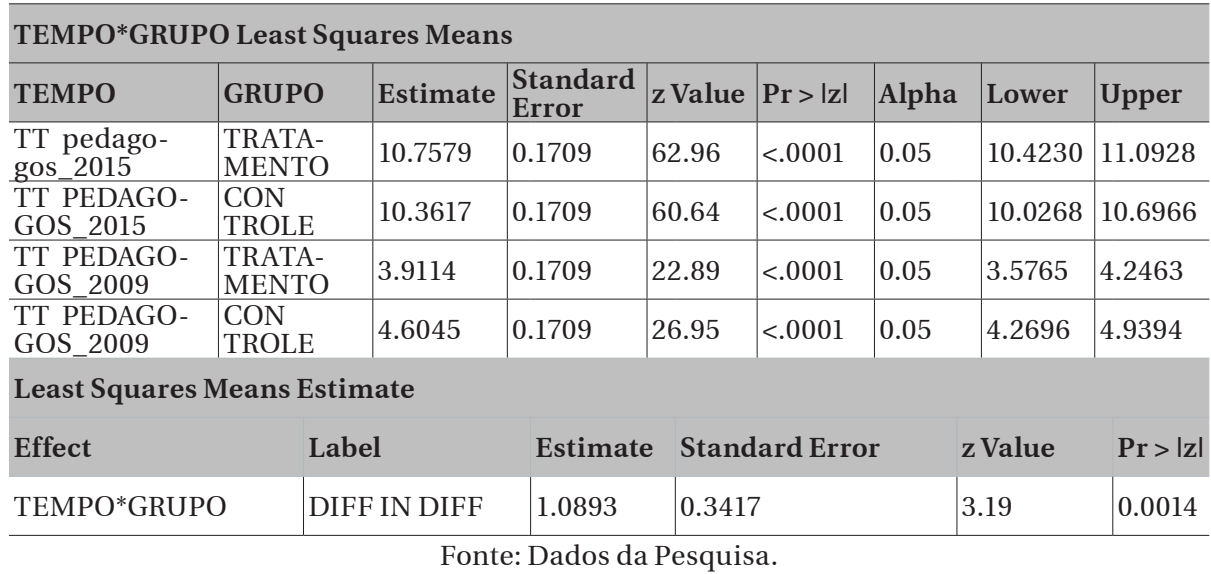

Importante ressaltar também que o impacto positivo do Parfor no número de pedagogos em atuação nas escolas se mostra significativo mesmo no contexto em que todas as escolas públicas, participantes ou não do Parfor, tiveram um aumento na média de professores licenciados em Pedagogia a sua disposição. Conforme pode ser observado na Figura 5, as escolas do grupo controle saem, em 2009, de um patamar médio de quase cinco pedagogos contratados por unidade escolar para um pouco mais de 10, em 2015. Já entre as escolas beneficiadas pelo Parfor, o número de pedagogos aumenta de um patamar menor que quatro pedagogos, em média, por unidade escolar em 2009, para a média de quase 11, em 2015.

Figura 5 - Representação Gráfica Efeito do Parfor no Número Médio de Pedagogos Atuando nas Escolas Públicas - 2009 vs. 2015

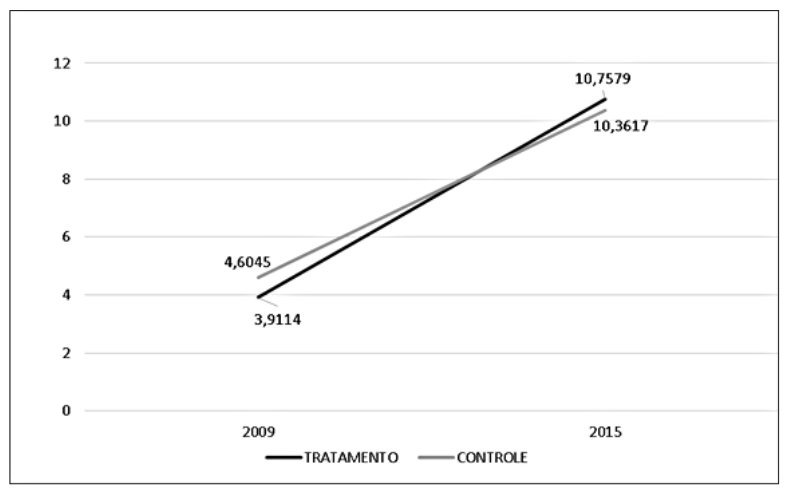

Fonte: Dados da Pesquisa. 
Dessa forma, é importante observar que a avaliação aqui realizada revelou que o Parfor não só atuou mais diretamente nas escolas que, em média, apresentavam maior carência de pedagogos, como também contribuiu para que o resultado apresentado por essas escolas, em relação ao perfil de titulação do seu quadro de docentes, ficasse muito próximo ao apresentado pelas escolas do grupo de controle.

Conforme discutem Oliveira e Passador (2019), as evidências apresentadas pela avaliação de impacto das políticas públicas permitem separar o que funciona do não funciona, subsidiando intervenções futuras sobre a mesma política ou programa. No caso do efeito do Parfor no número de pedagogos atuando nas escolas públicas, as evidências parecem apontar para uma experiência exitosa do Plano, considerando seus objetivos. No entanto, a despeito da carência de estudos semelhantes que permitam comparar a magnitude do impacto aferido, é de supor que aportar apenas 1 professor a mais no quadro das escolas beneficiadas seja pouco. Por um lado, os dados do Censo Escolar apontam que a carência de pedagogos formados atuando na Educação Infantil e anos iniciais do Ensino Fundamental ${ }^{7}$ ainda não foi superada. Por outro, a melhoria no perfil de titulação dos professores promovida pelo Parfor não foi acompanhada de aumento na qualidade das escolas beneficiadas.

Conforme dados da Tabela 4, não há evidências de que o Parfor melhore a qualidade da educação. Apurou-se até um impacto negativo da ordem de -0.05 pontos na nota do Ideb das escolas participantes, mas com probabilidade de erro muito alto nessa estimativa (superior a $40 \%$ ). Portanto, sem validade.

Tabela 4 - Efeito do Parfor no Ideb 2009 vs. 2015

\begin{tabular}{l} 
TEMPO*GRUPO Least Squares Means \\
\begin{tabular}{l|l|l|l|l|l|l|l|l} 
TEMPO & GRUPO & Estimate & $\begin{array}{l}\text { Standard } \\
\text { Error }\end{array}$ & z Value & Pr > |z| & Alpha & Lower & Upper \\
\hline Ideb_2015 & $\begin{array}{l}\text { TRATA } \\
\text { MENTO }\end{array}$ & 5.1849 & 0.02890 & 179.40 & $<.0001$ & 0.05 & 5.1282 & 5.2415 \\
\hline Ideb_2015 & CON TROLE & 5.4665 & 0.02890 & 189.15 & $<.0001$ & 0.05 & 5.4099 & 5.5231 \\
\hline Ideb_2009 & $\begin{array}{l}\text { TRATA } \\
\text { MENTO }\end{array}$ & 4.3603 & 0.02890 & 150.87 & $<.0001$ & 0.05 & 4.3037 & 4.4169 \\
\hline Ideb_2009 & CON TROLE & 4.5951 & 0.02890 & 159.00 & $<.0001$ & 0.05 & 4.5385 & 4.6517 \\
\hline Least Squares Means Estimate & Label & & Estimate & $\begin{array}{l}\text { Standard } \\
\text { Error }\end{array}$ & z Value & Pr > |z| \\
\hline Effect & DIFF IN DIFF & -0.04683 & 0.05780 & -0.81 & 0.4178 \\
\hline
\end{tabular} \\
\hline
\end{tabular}

Fonte: Dados da Pesquisa.

Os dados indicam que, aparentemente, o Parfor não foi capaz de interferir de forma significativa na tendência de desempenho das escolas participantes no Ideb, índice que mede a qualidade da educação básica no Brasil. No entanto, é preciso considerar que, além da formação 
Impacto do Parfor nas Escolas Públicas do Ensino Fundamental

dos professores, outros elementos podem concorrer para os resultados alcançados pelas escolas nesse índice.

Conforme apontam Ell et al. (2019), a formação inicial de professores relaciona-se ao aprendizado dos alunos, mas essa relação é afetada pela interveniência de outros elementos que compõem o sistema educacional. Para as autoras, a aprendizagem dos alunos é resultado de vários sistemas complexos sobrepostos, podendo ocorrer em função dos conhecimentos e práticas dos professores, mas também em função da política educacional que dá suporte ao processo de ensino-aprendizagem, bem como de características biossociais dos próprios alunos. Além disso, as autoras destacam que, no contexto da formação inicial, existe a necessidade de estruturas adequadas - tais como geração de conhecimento por meio de pesquisas, consultorias etc. - para garantir que os elementos teóricos apropriados e os instrumentais técnicos atualizados estejam disponíveis aos professores e reverberem na aprendizagem de alunos.

Há que se considerar, ainda, que os cursos de Pedagogia oferecidos pelo Parfor estão inseridos no contexto de deficiências dos cursos brasileiros de Pedagogia. Conforme apontado por Gatti (2010), há carência de conteúdos formativos diretamente afetos à docência (como ensinar), bem como daqueles associados às disciplinas a serem ministradas na educação básica (o quê e o porquê ensinar). Já Mascarenhas e Franco (2017) sugerem que a carga horária prevista para a curso de Pedagogia é insuficiente para formar com qualidade perfis de diferentes profissionais a um só tempo. Além disso, aponta para a necessidade de reestruturação das orientações curriculares previstas para o curso no que tange à organização de dois trajetos formativos: um focado na licenciatura, com vistas a uma densa formação do professor das séries iniciais e educação infantil; e outro, no bacharelado, para administração, coordenação e gestão escolar.

Aparentemente, considerando as contribuições de Souza (2017), o Parfor não ofereceu aporte teórico e instrumental técnico de forma a garantir um padrão de qualidade semelhante entre os cursos. Além disso, o Parfor não ofereceu suporte às condições estruturantes do sistema educacional que possuem potencial de interferir no resultado final do curso, tais como: suporte ao processo de formação em serviço do professor, suporte aos professores em formação carentes, entre outras.

Assim, graficamente, o modelo da diferença em diferença para o impacto da formação de pedagogos pelo Parfor no Ideb - anos iniciais - das escolas beneficiadas pode ser observado na Figura 6. Nela demonstra-se que o Ideb das escolas que tiveram professores licenciados em Pedagogia pelo Parfor é, em média, menor que aquelas do grupo de controle e que ambos cresceram entre 2009 e 2015. No entanto, os dados da pesquisa não permitem precisar em que medida o Parfor contribuiu para o crescimento apurado. A única evidência que os dados demonstram é que o Parfor, no caso dos cursos de Pedagogia, atuou mais nas escolas com Ideb mais fracos, quando comparado ao controle. 
Figura 6 - Representação Gráfica Efeito do Parfor na Média Apurada pelo Ideb - 2009 vs. 2015

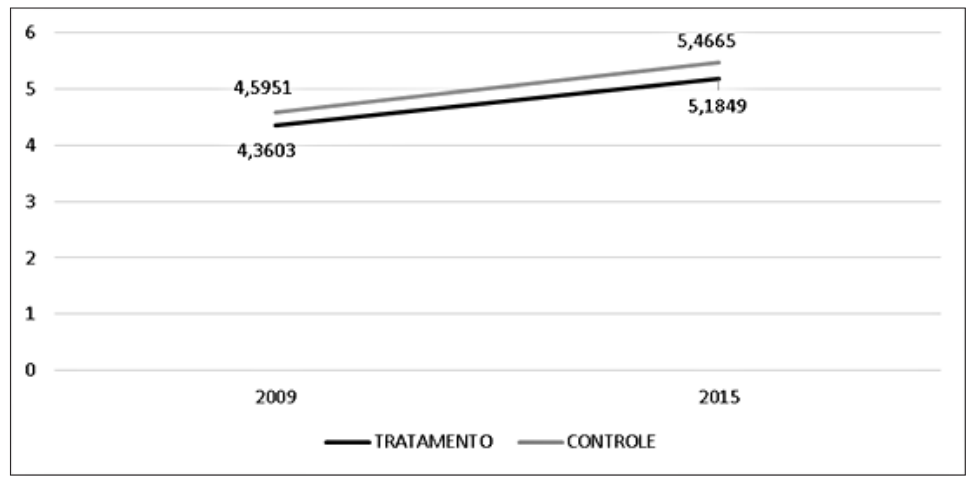

Fonte: Dados da Pesquisa.

Por fim, cabe destacar que do ponto de vista dos dados disponíveis nessa pesquisa, é preciso considerar que, conforme relatado na descrição metodológica desta análise, a maior parte das escolas pertencente ao grupo de tratamento contou, em 2015, com apenas um único pedagogo formado entre 2009 e 2014 pelo Parfor. Esse dado chama a atenção pela possibilidade de que o impacto do Parfor sobre a qualidade das escolas também tenha sido afetado pela pouca frequência de professores formados e atuantes em cada uma delas. Os dados disponíveis não permitiram controlar a influência da dispersão de beneficiários no impacto do Parfor no Ideb (mais de $80 \%$ das escolas do grupo de tratamento tinham apenas um professor participante do Parfor e esse desequilíbrio afetou as estimativas). No entanto, é possível supor que uma quantidade tão reduzida de professores formados pelo Plano nos quadros das escolas participantes, a despeito das interveniências apontadas por Ell et al. (2019), tenha sido, por si só, insuficiente para modificar, de fato e em função do Plano, a qualidade da educação medida pelo Ideb.

\section{Considerações Finais}

A ideia de que o desenvolvimento profissional dos professores se constitui num mecanismo essencial para melhorar o ensino e o desempenho dos alunos é compartilhado amplamente na literatura. No entanto, não há consenso sobre qual a melhor forma de promover esse desenvolvimento, tampouco sobre a melhor forma de medir as experiências formativas, quando da busca de evidências sobre quais delas funcionam ou não.

Inserida nesse contexto teórico, a presente análise buscou aferir a existência de causalidade entre as ações do Parfor, a melhoria do perfil de titulação do quadro docente e a qualidade das escolas públicas de ensino fundamental - anos iniciais. Além disso, este estudo buscou contribuir com a formulação de desenhos metodológicos de pesquisas, 
Impacto do Parfor nas Escolas Públicas do Ensino Fundamental

utilizando a técnica estatística DD com uma alternativa viável para atender às recomendações de validade e confiabilidade das análises discutidas na literatura da área.

Os resultados obtidos revelaram que as ações promovidas pelo Parfor garantem, pelo menos um pedagogo a mais em atuação nas escolas públicas dos anos iniciais do ensino fundamental beneficiadas, contribuindo para melhoria do perfil de qualificação dos professores em atuação. Todavia, quando se observa o impacto do Plano na qualidade dessas escolas, os resultados apresentados pelo DD não foram conclusivos, apesar da expectativa de que políticas públicas voltadas à formação de professores repercutam positivamente na aprendizagem de alunos (Delors, 1997; OCDE, 2011, 2013, 2018).

Por isso, torna-se importante destacar duas informações subjacentes a esses resultados. A primeira delas tem a ver com a moda da distribuição dos professores formados pelo Parfor entre as escolas beneficiadas. A frequência que mais se repete no grupo de tratamento é a de um professor por escola, permitindo supor, como hipótese, que a frequência reduzida de titulados por escola tenha influenciado a ausência de impacto significativo do Parfor na qualidade das escolas. Os dados não permitiram fazer o contraste entre o conjunto das escolas que beneficiada com apenas um professor, em relação às que foram beneficiadas com mais de um professor titulado em Pedagogia do Parfor. Dessa forma, é recomendável que a referida hipótese possa ser testada em pesquisa futura, previamente desenhada para controlar os resultados do modelo formativo em função do número de egressos. Os dados disponíveis neste estudo não permitiram realizar a análise sugerida.

A segunda informação que os resultados trazem e que merece destaque, refere-se aos números apresentados anteriormente na Figura 3 . De acordo com esses dados, cerca de $50 \%$ dos alunos do Parfor formados entre 2009 e 2014, supostamente professores da educação básica, não apareceram no Censo Escolar 2015. Além de um indicador preocupante para a eficácia de uma política pública que pretende formar professores em serviço, mas cujos alunos em sua maioria não figuram nas estatísticas educacionais como professores, essa informação é crítica para a avaliação do impacto do Parfor. De acordo com os dados apurados, a maioria dos professores formados pelo Parfor está fora do sistema de educação básica, afetando negativamente não só os resultados do Plano no atendimento à demanda por formação, como também a expectativa de impacto de professores formados no Ideb das escolas, conforme já pontuado no parágrafo anterior.

Vale observar, ainda, na interpretação desses dados a perspectiva trazida por Ell et al. (2019), de que a formação inicial de professores se relaciona ao aprendizado dos alunos, mas essa relação é afetada pela interveniência de outros elementos que compõem o sistema educacional. Para as autoras, a aprendizagem dos alunos é resultado de vários sistemas complexos sobrepostos, podendo ocorrer em função dos conhecimentos e práticas dos professores, mas também em função da política 
educacional que dá suporte ao processo de ensino-aprendizagem, bem como de características biossociais dos próprios alunos. Além disso, elas destacam que, no contexto da formação inicial, há a necessidade de estruturas adequadas - tais como geração de conhecimento por meio de pesquisas, de consultorias etc. - para garantir que os elementos teóricos apropriados e os instrumentais técnicos atualizados contribuam com a aprendizagem dos estudantes.

É preciso destacar, também, que a questão dos modelos formativos precisa ser mais bem resolvida no desenvolvimento do Parfor. Ao longo do estudo, não foi possível identificar as características específicas dos cursos de Pedagogia oferecidos pelo Parfor que os identificassem em clusters. A diversidade de modelos formativos, nos termos descritos por Souza (2017), aliada à ausência de informações que permitissem classificar os cursos em função de suas características, inviabilizou a intenção de observar diferenças entre os modelos formativos do Parfor no impacto do Programa na qualidade das escolas.

Assim, considerando os dados e informações analisados nessa avaliação de impacto, pode-se considerar, a despeito da contribuição do Parfor na melhoria do perfil de qualificação dos professores em atuação nas escolas públicas, que há necessidade de ajustes de execução do Plano. O objetivo de atender à demanda por formação de professores das redes públicas de educação, expresso na Portaria de criação do Parfor e representado neste trabalho pelo indicador proxy número de professores diplomados, foi cumprido. No entanto, a melhoria do perfil de qualificação profissional dos docentes não foi acompanhada nos termos apurados nesta pesquisa, da melhoria da qualidade da educação medida pelo Ideb.

Recebido em 12 de agosto de 2020 Aprovado em 5 de fevereiro de 2021

\section{Notas}

1 Indicador oficial de qualidade da educação brasileira pelo Plano Nacional de Educação (PNE), Lei no 13.005, de 24 de junho de 2014 (Brasil, 2014).

2 Decreto no 6.755, de 29 de janeiro de 2009 (Brasil, 2009a).

3 Portaria Normativa no 9, de 30 de junho de 2009 (Brasil, 2009b).

4 Indicador oficial de qualidade da educação brasileira pelo Plano Nacional de Educação (PNE), Lei nº 13.005, de 24 de junho de 2014 (Brasil, 2014).

5 A proposta da base docente emergiu do movimento dos educadores organizados na Associação Nacional pela Formação dos Profissionais da Educação (Anfope), a partir da concepção da docência como elemento central na formação do pedagogo, com vistas à superação da dicotomia entre a licenciatura e o bacharelado, então identificada. Essa proposta foi incorporada às Diretrizes Curriculares do curso de Pedagogia pela Resolução CNE/CP No 1 , de 15 de maio de 2006 (Brasil, 2006).

6 Artes, Artes Cênicas, Artes e Mídia, Artes Plásticas, Artes Visuais, Biologia, Ciência da Educação, Ciências, Ciências Biológicas, Ciências da Religião, Ciências Físicas, Ciências Naturais, Ciências Sociais, Educação [...], Estudos Religiosos, 
Impacto do Parfor nas Escolas Públicas do Ensino Fundamental

Estudos Sociais, Filosofia, Física, Formação de Professores [...], Geografia, Gestão da Educação, História, História da Cultura, Informática, Informática Educacional, Língua [...], Linguagem de Sinais, Linguística [...], Literatura, Matemática [...], Música, Pedagogia [...], Psicologia, Psicopedagogia, Química, Saúde Pública, Sociologia, Teatro, Tecnologia da Educação e Teologia.

7 Em 2015, foram contabilizados pouco mais de 1.197.000 professores atuando nesses níveis escolares, dos quais apenas cerca de $48 \%$ eram titulados em Pedagogia (Inep, 2015).

\section{Referências}

AERA. Statement on Use of Value-Added Models (VAM) for the Evaluation of Educators and Educator Preparation Programs. Educational Researcher, Washington, v. 44, n. 8, p. 448-452, nov. 2015.

ARAÚJO, Viviane Patricia Colloca. A Multiculturalidade nas Políticas Educacionais e a Formação de Professores: Brasil e Portugal. 2009. 436 f. Tese (Doutorado em Educação) -. Universidade Federal de São Carlos, São Carlos, 2009.

BOYD, Donald et al. Complex by Design: investigating pathways into teaching in New York city schools. Journal of Teacher Education, v. 57, n. 2, p. 155-166, mar./abr. 2006.

BRASIL. Lei n 9.394, de 20 de dezembro de 1996. Institui as diretrizes e bases da educação nacional. Diário Oficial [da] República Federativa do Brasil, Brasília, DF, 20 dez. 1996. Disponível em <http://www.planalto.gov.br>. Acesso em: 30 jun. 2019.

BRASIL. Ministério da Educação. Conselho Nacional de Educação. Resolução CNE/CP no 1 , de 18 de fevereiro de 2002, que institui Diretrizes Curriculares Nacionais para a Formação de Professores da Educação Básica, em nível superior, curso de licenciatura, de graduação plena. Diário Oficial [da] República Federativa do Brasil, Brasília, DF, 19 fev. 2002. Disponível em: <http://portal.mec. gov.br/conselho-nacional-de-educacao/atos-normativos--sumulas- pareceres -e-resolucoes? $\mathrm{id}=12816>$. Acesso em 8 out. 2019.

BRASIL. Ministério da Educação. Conselho Nacional de Educação. Resolução CNE/CP no 1, de 15 de maio de 2006, que institui Diretrizes Curriculares Nacionais para o Curso de Graduação em Pedagogia, licenciatura. Brasília, DF, 16 maio. 2006. Disponível em: <http:// meclegis.mec.gov.br >. Acesso em 8 out. 2019.

BRASIL. Decreto $n^{\circ}$ 6.755, de 29 de janeiro de 2009. Institui a Política Nacional de Formação de Profissionais do Magistério da Educação Básica, disciplina a atuação da Capes no fomento a programas de formação inicial e continuada e dá outras providências. Diário Oficial [da] República Federativa do Brasil, Brasília, DF, 30 jan. 2009a. Disponível em: <http://www.planalto.gov.br>. Acesso em: 30 jun. 2019.

BRASIL. Ministério da Educação. Portaria Normativa no 9, de 30 de junho de 2009. Institui o Plano Nacional de Formação dos Professores da Educação Básica no âmbito do Ministério da Educação. Diário Oficial [da] República Federativa do Brasil, Brasília, DF, 01 jul. 2009b. Disponível em: <http:// meclegis.mec. gov.br >. Acesso em: 30 jun. 2011.

BRASIL. Lei n 13.005, de 24 de junho de 2014 (BRASIL, 2014). Plano Nacional de Educação. Diário Oficial [da] República Federativa do Brasil, Brasília, 25 jun. 2014. Disponível em: <http://www.in.gov.br>. Acesso em: 30 jun. 2019. 
BRASIL. Ministério da Educação. Conselho Nacional de Educação. Resolução CNE/CP no 2, de $1^{\circ}$ de julho de 2015, que define as Diretrizes Curriculares Nacionais para a formação inicial em nível superior (cursos de licenciatura, cursos de formação pedagógica para graduados e cursos de segunda licenciatura) e para a formação continuada. Diário Oficial [da] República Federativa do Brasil, Brasília, DF, 02 jul. 2015. Disponível em: <http://portal.mec.gov.br/ conselho-nacional-de-educacao/atos-normativos--sumulas-pareceres-eresolucoes? id=12816>. Acesso em 8 out. 2019.

BRASIL. Decreto no 8.752, de 9 de maio de 2016. Revoga o Decreto 6.755/2009 e dispõe sobre a Política Nacional de Formação dos Profissionais da Educação Básica. Diário Oficial [da] República Federativa do Brasil, Brasília, DF, 10 mai. 2016. Disponível em: <http://www.planalto.gov.br >. Acesso em: 30 jun. 2019.

BRASIL. Ministério da Educação. Conselho Nacional de Educação. Resolução CNE/CP no 2, de 20 de dezembro de 2019 - Define as Diretrizes Curriculares Nacionais para a Formação Inicial de Professores para a Educação Básica e institui a Base Nacional Comum para a Formação Inicial de Professores da Educação Básica (BNC-Formação). Diário Oficial [da] República Federativa do Brasil, Brasília, DF, 20 dez. 2019. Disponível em: <http://portal.mec.gov. br/conselho-nacional-de-educacao/atos-normativos--sumulas-pareceres-eresolucoes?id=12816>. Acesso em: 2 fev. 2020.

CARD, David; KRUEGER, Alan. Minimum Wages and Employment: a case study of the fast food industry in New Jersey and Pennsylvania. The American Economic Review, Pittsburgh, v. 84, n. 4, p.772-793, set. 1994.

COCHRAN-SMITH, Marilyn; ZEICHNER, Kenneth (Org.). Studying Teacher Education: the report of the AERA panel on research and teacher education. Mahwah: Lawrence Erlbaum Associates, 2005.

COCHRAN-SMITH, Marilyn et al. Holding Teacher Preparation Accountable: a review of claims and evidence. Boulder: National Education Policy Center, 2016. Disponível em: <https://nepc.colorado.edu/sites/default/files/pb_cochransmith_teacher_prep_0.pdf >. Acesso em: 19 nov. 2019.

DARLING-HAMMOND, Linda; YOUNGS, Peter. Defining 'highly qualified teachers': what does 'scientifically-based research' actually tell us. Educational Researcher, Washington, v. 31, n. 9, p. 13-25, dez. 2002.

DELORS, Jacques (Org.). Educação, Tesouro a Descobrir. Relatório para a Unesco da Comissão Internacional sobre Educação para o século XXI. Paris; Brasília: UNESCO/Edições ASA/Cortez, 1997. (Edição brasileira).

DIMICK, Justin; RYAN, Andrew. Methods for Evaluating Changes in Health Care Policy: the difference-in-differences Approach. Journal of the American Medical Association, Chicago, v. 312, n. 22, p. 2401-2402, dez. 2014.

ELL, Fiona et al. Conceptualising the Impact of Initial Teacher Education. The Australian Educational Researcher, v. 46, n. 1, p. 177-200, mar. 2019.

FERNANDES, Reynaldo. Índice de Desenvolvimento da Educação Básica (Ideb). Brasília: Instituto Nacional de Estudos e Pesquisas Educacionais Anísio Teixeira, 2007. (Série Documental. Textos para Discussão 26).

FIRPO, Sérgio; PIERI, Renan. Avaliando os Efeitos da Introdução de Computadores em Escolas Públicas Brasileiras. Revista Brasileira de Inovação, Campinas, v. 11, n. especial, p. 153-190, jul. 2012.

FRANCO, Maria Amélia Santoro; LIBÂNEO, José Carlos; PIMENTA, Selma Garrido. Elementos para a Formulação de Diretrizes Curriculares para Cursos de 
Impacto do Parfor nas Escolas Públicas do Ensino Fundamental

Pedagogia. Cadernos de Pesquisa, São Paulo, v. 37, n. 130, p. 63-97, jan./abr. 2007.

GATTI, Bernardete. Formação de Professores no Brasil: características e problemas. Educação \& Sociedade, Campinas, v. 31, n. 113, p. 1355-1379, out./dez. 2010.

GOLDHABER, Dan. What Do Value-Added Measures of Teacher Preparation Programs Tell Us? carnegie foundation for the advancement of teaching, Stanford, CA: Carnegie Knowledge Network. What We Know Series: Value-Added Methods and Applications, p. 14, nov. 2013. Disponnível em: <http://www.carnegieknowledgenetwork.org/wp-content/uploads/2013/11/CKN-GoldhaberTeacherPrep_Final_11.7.pdf>. Acesso em: 01 jun. 2020.

HANUSHEK, Eric; WÖßMANN, Ludger. Does Educational Tracking Affect Performance and Inequality? Differences- in-Differences Evidence Across Countries. The Economic Journal, Oxford, v. 116, n. 510, p. C63-C76, mar. 2006.

HECKMAN, James; ICHIMURA, Hidehiko; TODD, Petra. Maching as an Econometric Evaluation Estimator: evaluating a job training programme. The Review of Economic Studies, London, v. 64, n. 4, p. 605-654, out. 1997.

INEP. Sinopse Estatística do Professor da Educação Básica 2009. Brasília, 2009. Disponível em: <http://www.inep.gov.br>. Acesso em: 20 jun. 2020.

INEP. Microdados do Censo Escolar 2015. Brasília, 2015. Disponível em: <http:// www.inep.gov.br>. Acesso em: 20 jun. 2020

LIBÂNEO, José Carlos. Reflexividade e Formação de Professores: outras oscilações do pensamento pedagógico brasileiro? In: PIMENTA, Selma Garrido; GHEDIN, Evandro (Org.). Professor Reflexivo no Brasil: gênese e crítica de um conceito. São Paulo: Cortez, 2008. P. 53-79.

MASCARENHAS, Aline Daiane Nunes; FRANCO, Maria Amélia Santoro. De Pedagogos a Professores: balanço de uma década das Diretrizes Curriculares dos Cursos de Pedagogia no Brasil. Revista Internacional de Formação de Professores, Itapetininga, v. 2, n. 1, p. 41-55, jan./mar. 2017.

MIHALY, Kata et al. Where You Come from or Where You Go? Distinguishing Between School Quality and the Effectiveness of Teacher Preparation Program Graduates. Center for Analysis of Longitudinal Data in Education Research, Washington, D.C. Working Paper 63, 41 p, jan. 2012 Disponível em: <https://files eric.ed.gov/fulltext/ED529178.pdf>. Acesso em: 01 jun. 2020.

OCDE. Building a High-Quality Teaching Profession: lessons from around the world. Paris: OECD Publishing, 2011. 65 p.

OCDE. Learning standards, teaching standards, and standards for school principals: a comparative study. OECD Education Working Papers, Chile, Centre of Study for Policies and Practices in Education (CEPPE), n. 99, 19 dez. 2013.

OCDE. Effective Teacher Policies: insights from Pisa. Paris: OECD Publishing, 2018, 163 p.

OLIVEIRA, Lilian Ribeiro de; PASSADOR, Claudia Souza. Ensaio Teórico Sobre as Avaliações de Políticas Públicas. Cadernos EBAPE.BR, Rio de Janeiro, v. 17, n. 2, p. 324-337, jun. 2019.

RIOS, Terezinha. Compreender e Ensinar: por uma docência da melhor qualidade. 8. ed. São Paulo: Cortez, 2010.

ROWAN, Leonie et al. Investigating the Effectiveness of Teacher Education for Early Career Teachers in Diverse Settings: the longitudinal research we have to have. The Australian Educational Researcher, v. 42, n. 3, p. 273-298, jul. 2015. 
SCHEIBE, Leda. Diretrizes Curriculares para o Curso de Pedagogia: trajetória longa e inconclusa. Cadernos de Pesquisa, v. 37, n. 130, p. 43-62, 2007.

SCHNEIDER, Barbara et al. Estimating Causal Effects Using Experimental and Observational Designs: a think tank white paper. Washington: American Educational Research Association, 2007.

SILVA JÚNIOR, Luiz Honorato da; PEDROSA, Beatriz Mesquita Jardim; SILVA, Márcio Francisco da. Avaliação dos Impactos do ICMS Socioambiental na Criação de Unidades de Conservação e Unidades de Tratamento de Resíduos Sólidos em Pernambuco: uma análise a partir do método de diferenças-em-diferenças. Revista Econômica do Nordeste, Fortaleza, v. 44, n. 2, p. 559-574, abr./jun. 2013. SLEETER, Christine. Toward Teacher Education Research that Informs Policy. Educational Researcher, Washington, v. 43 n. 3, p. 146-153, abr. 2014.

SOLÉ-OLLÉ, Albert; SORRIBAS-NAVARRO, Pilar. The Effects of Partisan Alignment on the Allocation of Intergovernmental Transfers: differences-in-differences estimates for Spain. Journal of Public Economics, Amsterdam, v. 92, n. 12, p. 2302-2319, dez. 2008.

SOUZA, Valdinei Costa. Qualidade da formação de pedagogos na perspectiva da oferta do Parfor Presencial. Educação e Pesquisa, São Paulo, v. 43, n. 1, p. 82-96, jan./mar. 2017.

YOON, Kwang Suk et al. Reviewing the Evidence on How Teacher Professional Development Affects Student Achievement. Washington, DC: U.S. Department of Education, Institute of Education Sciences, National Center for Education Evaluation and Regional Assistance, Regional Educational Laboratory Southwest. Issues \& Answers, n. 33, 2007. 62 p. Disponível em: <https://files.eric. ed.gov/fulltext/ED498548.pdf>. Acesso em: 19 nov. 2019.

Valdinei Costa Souza é doutora em Educação (UnB), Analista Sênior em Ciência e Tecnologia (Capes).

ORCID: https://orcid.org/0000-0001-5145-043X

E-mail: valdinei.souza@Capes.gov.br

Editora-responsável: Beatriz Vargas Dorneles

Este é um artigo de acesso aberto distribuído sob os termos de uma Licença Creative Commons Atribuição 4.0 Internacional. Disponível em: <http:// creativecommons.org/licenses/by/4.0>. 